\title{
Reference distorted prices
}

\author{
József Sákovics* \\ The University of Edinburgh
}

May 9, 2011

\begin{abstract}
I show that when consumers (mis)perceive prices relative to reference prices, budgets turn out to be soft, prices tend to be lower and the average quality of goods sold decreases. These observations provide explanations for decentralized purchase decisions, for people being happy with a purchase even when they have paid their "valuation", and for why trade might affect high quality local firms "unfairly".
\end{abstract}

\section{Introduction}

In this paper, I put forward a novel theory of consumer behavior in which people who have paid their willingness to pay (WTP) for a good or service are ex post not necessarily indifferent between having purchased it or not. This result follows

\footnotetext{
*This is the final version forthcoming in Quantitative Marketing and Economics, replacing previous drafts entitled "Reference price distortion". I thank Sridhar Moorthy, the Co-Editor, for his tireless effort to help me improve the manuscript. I am also grateful to Randy Bucklin, Dan Friedman, Gianni De Fraja, Botond Kőszegi, Carmen Matutes and Peter Sinclair, as well as audiences at the ESEM 2007, the 2007 mini-conference on "Behavioural Economics" in Edinburgh and the Theory seminar in Manchester for useful comments.
} 
from a new modelling perspective on the well-known phenomenon, that consumers form an expectation about the "right" price prior to shopping, and this - possibly subjective - view influences the worst acceptable terms of trade for them. The new insight is that as this WTP is influenced by factors unrelated to preferences, there can be a wedge between the price at which the consumer is just willing to trade (that is, her WTP) and the change of wealth at which she is indifferent between owning the good or not, a value that is strictly preference driven and independent of the purchasing environment, however broadly construed. Thus, consumers can derive a non-zero utility, relative to the status quo, even having bought at their WTP. I call this difference leftover utility. To bring the discussion closer to home, consider the following scenario:

You have joined the only fitness club in the neighborhood where you plan to live for the rest of your life. The sales executive bargained hard, so the joining fee made you just about indifferent between joining or not. Say, the fee you ended up paying was

\section{1. higher,}

\section{2. lower}

than what you had expected. Once you have "cooled off" and could form a precise opinion about how much you actually like to go to the club: How would you evaluate your deal on average?

I contend that - unless your economics training took the better of you - in the first case you would be moderately elated (positive leftover utility), while in the second somewhat disappointed (negative leftover utility). The idea is simple: when you buy something expensive - where expensive is determined in relation to what you expected to pay beforehand - you feel that you are paying too much and as a result (perhaps subconsciously) hold yourself back. Thus, even if you felt being pushed to the limit at the time of the transaction, the consumption value of the good will exceed the 
actual price you have paid. And the opposite happens when you purchase something cheaply, again in relative terms: you feel you are paying too little when you see a low price, ending up spending too much.

Existing - even behavioral - economic theory would predict that you would be indifferent between the two situations. In this paper, I develop a simple new model that captures the above phenomenon, and then derive a number of further testable predictions from it.

This contribution is intended as a further building block in the research program started by Richard Thaler (1980) towards a behaviorally based theory of consumer choice. It is based on the empirically well-established trait of consumer behavior, that consumers have a prior idea of what a certain item "should" cost, and this reference price affects their purchasing decision. ${ }^{1}$ Note that there is no universal procedure for the generation of this value, rather the process is context and person dependent. Obviously, past purchase prices, advertisements, hearsay, ethical considerations etc. could all play a role in the construction of a "rational expectation price." In a procedurally rational framework, the natural reference price is the literal Rational Expectations Equilibrium (REE) price, where the reference price bias of consumers is common knowledge, and they can solve for the fixed point that makes their expectation of the price set by producers correct.

The conceptual novelty of my approach is that instead of assuming that the reference price affects their preferences, ${ }^{2}$ in my model consumers have standard preferences but they behave as if the reference price distorted their perception of prices. There

\footnotetext{
${ }^{1}$ See Mazumdar et al. (2005) for a review of the substantial empirical literature on reference prices.

${ }^{2}$ This has been the approach taken by all the theoretical studies, e.g. Thaler (1985), Putler (1992), and more recently, Ariely et al. (2004), Heidhues and Kőszegi (2005, 2008) and Köszegi and Rabin (2006). Winer (1986) and his followers (see Biswas and Blair, 1991, Bell and Lattin, 2000, Briesch et al., 1997, Hardie et al., 1993, Kalyanaram and Winer, 1995) sidestep this issue by directly modelling the dependence of the probability of purchase on the difference between the actual and the reference price.
} 
is no presumption that they actually misperceive prices, rather this is just a proxy for a more complex psychological phenomenon, which nonetheless leads to the same behavior and has the same welfare consequences.

There is a vast literature about the factors that influence a consumer's perception of how good a price is (see, e.g. Jacoby and Olson, 1977, Zeithaml, 1988). Niedrich et al. (2001) present a conceptual framework for the evaluation of price attractiveness based on the information integration theory of Anderson (1981). They decompose the mapping from actual prices to a price attractiveness scale into three parts. The valuation function encodes each observed price as a subjective value, the integration function forms a single subjective judgement value based on the set of subjective values, finally the response function maps the judgement value into a price attractiveness rating. While sharing its spirit, I slightly depart from this framework, as my mapping is from actual prices to perceived prices, which then consumers use in standard economic models of rational choice.

The nature of the misperception needed to explain observed behavior is simple: any price that is above the reference price seems even higher, and any price below the reference price seems even lower than it actually is. It is as if consumers were wearing glasses, where the concavity/convexity of the lenses was determined by whether the reference price is higher or lower than the price currently observed. As a further distinction from the literature, I do not require that consumers be loss averse (though I allow for it), not even in the limited sense of price distortions being higher upwards than downwards from the reference price.

The modelling of reference-price bias in the price - rather than the utility - dimension seems to be the natural approach, after all, the reference price itself is a price. An immediate consequence of this shift in the location of the distortion is that the welfare effects of reference-price bias become easier to deal with. The standard approach modifies the decision maker's preferences in order to accommodate the bias. An unintended (but unavoidable) consequence of this is that the welfare measures get distorted. If instead we leave the preferences intact and account for the bias via a 
perception error, our welfare calculations will be unbiased. ${ }^{3}$ This is the very reason why the model can explain the existence of leftover utility, which is subsumed in the welfare distortion in the standard approach.

Putting welfare considerations to the side, the new framework is shown to be more general than even the natural extension to divisible commodities of Thaler's (1985) transaction utility model, originally formulated for single-unit purchases. In particular, it can capture situations where the distortion fades when the distance between the price and the reference price is large. I discuss the comparison between the two approaches in detail in Section 5.

I derive a number of specific predictions for consumer and firm behavior. In the context of consumer demand, I first show that, depending on the relative position of the actual price to the reference price, one can be willing to spend more or less than one's intrinsic valuation of a good, just as in the club joining example above. ${ }^{4}$ Second, for divisible goods, I show that the amount spent on a good will vary in a somewhat counter-intuitive way: when the price is below (above) the reference price the consumer spends more (less) than when she correctly predicts the price. Note that this is in the absence of a stockpiling motive. When I incorporate the previous finding into a multi-good scenario, I find that the insight of "the more the cheese costs the less you can spend on wine" does no longer apply: if the price of a good is unexpectedly high, you are likely to spend more on complementary goods, unlike

\footnotetext{
${ }^{3}$ An intermediate approach, allowing for extra utility derived from purchasing at a certain relative price - say, getting a "kick" out of buying something cheap - is perhaps the ultimate solution.

${ }^{4}$ The same formulation can be used to model seller behavior. For example, by assuming that a seller has as reference price the price for which she had bought an item, we can explain why sellers hold out for "unreasonably" high prices in an economic downturn, when they are likely to realize a (nominal) loss relative to the purchase price. Genesove and Mayer (2001) claim that their empirical results on this phenomenon validate the loss aversion hypothesis. However, they are only looking at losses, not at gains. Therefore, what they really show is not that losses have larger effects on utility than gains, but that losses have an amplified effect relative to the standard theory. But that means that their findings support my theory just as well.
} 
what the received theory predicts. ${ }^{5}$

Next, I turn to the standard consumer choice problem of choosing the optimal consumption bundle given a budget constraint. In this context, my formulation leads to notional/soft budgets, ${ }^{6}$ as these are met not for the true prices, rather the perceived ones. This is feasible as long as the consumer is only faced with her hard budget constraint periodically, not at every purchasing decision. I present a simple model of sequentially distributed consumer choice to support this behavior.

In the context of a market for a single homogeneous good, where the reference price is given by the REE price, I show that equilibrium prices in Cournot markets would tend to be lower than in the neoclassical model, for any market structure (including monopoly) except perfect competition. This result also generalizes to horizontally differentiated goods, since it is driven by the increase in the price elasticity of demand as a result of the price distortion. The aggregate welfare effect is positive, with the consumers benefiting by more than what the producers lose.

When there is vertical differentiation, I show that the loss of profit of a high quality incumbent due to the entry of a low quality competitor is increased as a result of reference price dependence. This finding provides a partial explanation of why local high quality firms may be driven out of the market by cheap low quality

\footnotetext{
${ }^{5}$ Janakiraman et al. (2006) provide an experimental design that is partially suited to test my model's predictions. In their main study the subjects are asked to minimize the aggregate cost of stocking a dozen different goods over 35 periods. Their inventory of any good cannot exceed 4 . They can go shopping in each period at a fixed cost, but they must shop in case they stock out of something (stocks are depleted "randomly" from the point of view of the subjects). Upon such "mandatory" shopping trips the price of the stocked-out item is raised or lowered by $80 \%$. They find that there is a negative spill-over effect: if prices are high (low) in a category the consumer spends more (less) on the other categories. This squares with my prediction.

${ }^{6}$ Deaton (1977) has nearly discovered soft budget constraints in a model where there is inflation but the consumers only observe the price increase of a single good at a time. If they (wrongly) believe that the prices of the other goods have stayed constant, they will spend less than optimal (and less than mentally budgeted) on the good at question. He then goes on to look at the aggregate behavior of the economy and does not follow up the consequences on individual behavior.
} 
imports even when this is not efficient.

\section{The reference-distorted price}

Based on the evidence cited above, my first axiom posits the existence of a reference price, which captures the consumer's "best guess" of how much the item should cost, before she observes the actual price.

Axiom 1 Consumers have a preconceived idea about the price of each good, which we call the reference price. Different consumers - or the same consumer in different contexts - need not attach the same reference price to the same good.

Taking the existence of reference prices as given, the relevant question is: how do they influence the consumers' purchasing decisions? One road to go down could be to assume that the difference between the reference price and the actual price directly enters the consumers' utility function. This is the path that the existing theoretical approaches have taken (c.f. footnote 2). I make the alternative assumption that the reference price does not affect the utility derived from purchasing an item. Instead, all the action takes place via an adjustment in the perception of the actual price, which then modifies consumer behavior exclusively through its effect on expenditure, without affecting preferences. As this approach keeps preferences unchanged, it imposes strict discipline on the way that reference-price effects can influence a consumer's decisions and especially her welfare.

The perceived price is generated as a function of the actual and the reference prices:

Axiom 2 Each consumer is endowed with a price function, $P(. ;),. \mathbb{R}_{+}^{2} \rightarrow \mathbb{R}$, which for every reference price, $p^{R}$, maps from the actual prices, $p$, into perceived prices, $p^{P}=P\left(p ; p^{R}\right)$. Consumers treat the perceived price as a sufficient statistic for all price-related information. 
A crucial element of my model is the description of the way reference prices distort the actual prices. My intention is to impose the minimal structure: ideally the price function should be estimated from observed behavior. Nevertheless, there are some guiding principles towards the characterization. First, the price function should capture the empirically established and sensible idea that the subjective effect of a reference price is to make a price that is higher than it seem (even) higher (a negative "sticker shock"); and a price that is lower than it seem (even) lower (a positive "sticker shock"). Second, when the actual price coincides with the reference price there should be no distortion. Finally, one would expect the perceived price to be increasing in the actual price and decreasing in the reference price. Summing up, I propose the following:

Axiom 3 The price function has the following properties (for $x, y, z \geq 0$ ):

a) $P(x ; y)>x$ if $y<x$

b) $P(x ; y)<x$ if $y>x>0$;

c) $P(x ; x)=x \quad \forall x$;

d) $P(x ; y)>P(z ; y)$ if $z<x \forall y$.

e) $P(x ; z)>P(x ; y)$ if $z<y \forall x>0$.

Note that while the axiom does not rule out negative perceived prices, it is compatible with a setting where $P(0 ;.) \equiv 0$ and perceived prices are non-negative.

In order to simplify the proofs and to clarify intuition, I make the innocuous assumption that the price function is also differentiable, except possibly at the reference price. This allows for - but does not require ${ }^{7}$ - the equivalent of loss aversion (higher directional derivative of $P(p ; y)$ at $p=y$ from above than from below $y$ ) to hold in

\footnotetext{
${ }^{7}$ The jury is still out on how general the existence of loss aversion is, especially in the context of frequently purchased grocery products (c.f. Bell and Lattin, 2000), which is one of this model's prime applications.
} 
this scenario. Additionally, in order to reconcile the use of real analysis with the actual discreteness of prices, and in view of the literature on the relevance of the last digits in retail pricing (c.f. Schindler and Kibarian, 1996), I assume that the slope of the price function from below is strictly larger than 1 at the reference price - Axiom 3 only implies that it is weakly larger than 1 . This ensures that the distortion resulting from a marginal price reduction from the reference price is positive. As we will see later, this condition is behind the strict increase in price elasticities that drive many of the results.

Assumption $1 P(x ; y)$ is differentiable in its first argument, except for a possible kink at $y$. Moreover, its left derivative at $x=y$ is strictly larger than 1.

In most of the paper I will only use Axioms 1-3 (and Assumption 1) to derive my results. However, for illustrational purposes it is useful to have a concrete functional form in mind. I propose the following: ${ }^{8}$

$$
P_{\alpha}\left(p ; p^{R}\right):=p\left(1+\alpha \frac{p-p^{R}}{p^{R}}\right) .
$$

Here, $\alpha \geq 0$ is a parameter measuring the intensity of price distortion, which may vary across consumers, and perhaps even for the same consumer across different contexts. When $\alpha=0$, there is no distortion, $P_{0}(p ;.) \equiv p$, while the size of distortion, $\left|P_{\alpha}\left(p ; p^{R}\right)-p\right|$, is increasing in $\alpha$. It is straightforward to check that $P_{\alpha}(. ;$.$) satisfies$ Axiom 3 and Assumption 1.

\footnotetext{
${ }^{8}$ This price function is convex. If that is considered inappropriate, say because we might expect the reference price effect to decrease for very high prices, a logistic function could be used as an alternative. Here I opt for simplicity.
} 


\section{The effects of reference distorted price percep- tion (RDP) on consumer demand}

\subsection{Single-unit purchases}

The simplest formulation of consumer choice is to look at a single binary purchasing decision - like buying or not a durable good - in isolation. A consumer is going to buy if the price does not exceed her willingness to pay (WTP). A consumer's WTP for an object is a basic building block for all trade models, whether disaggregate (say, bilateral bargaining) or aggregate (say, a competitive market). Hence, the reference price effect on WTP can have far-reaching consequences. With RDP, the highest actual price the consumer is willing to pay, denoted by $v^{R}$, is implicitly defined by the highest perceived price, $p^{P}=P\left(p ; p^{R}\right)$, she is willing to pay. Formally

$$
U(w ; 0)=U\left(w-P\left(v^{R} ; p^{R}\right) ; 1\right)
$$

where $w$ denotes wealth, and the second argument of the (indirect) utility function $U(. ;$.$) is an indicator function, showing whether the consumer owns the item. In$ words, the consumer is willing to pay up to the actual price at which the perceived price would make her indifferent between buying and not buying. This definition not only implies that her WTP is a function of the reference price she had in mind, but it also captures the exact form of this relationship. Even without specifying the utility function we can conclude that by Axiom 3e), and consistent with intuition, the WTP is increasing in the reference price: the more expensive you expect an item to be, the more you are willing to pay for it.

It is important to observe, that according to (2) the consumer may decide to purchase the item even when the actual price exceeds her wealth. I will explore the implications of this "soft budget constraint" in Section 3.4. 


\subsubsection{Leftover utility}

Leftover utility is the utility the consumer actually derives net of the utility she thought she was deriving while under the effect of RDP, evaluated at the actual price of $v^{R}$. Hence it is given by

$$
U\left(w-v^{R} ; 1\right)-U\left(w-P\left(v^{R} ; p^{R}\right) ; 1\right)=U\left(w-v^{R} ; 1\right)-U(w ; 0)
$$

As it is clear from (3) an alternative definition is that leftover utility is - the consumer's share of - the gains from trade at the actual price the consumer is willing to pay, $v^{R}$.

\subsubsection{Valuation vs. willingness to pay}

The wealth reduction that would make a consumer indifferent between buying or not is defined as her valuation, which we will denote by $v$. Its defining equation is then

$$
U(w ; 0)=U(w-v ; 1) .
$$

As this is a "priceless" definition, a consumer's valuation is not affected by RDP and therefore it coincides with her WTP in the standard model. However, in the reference-price context - as follows from (2) and the fact that utility is increasing in wealth - it is the price perceived by the consumer when she is charged her WTP, rather than the WTP itself, that equals her valuation: $P\left(v^{R} ; p^{R}\right)=v$. This observation has some clear implications.

Proposition 1 Given Axioms 1-3 the following hold:

i) If her reference price exceeds her valuation for an item, then the consumer is willing to spend more than her valuation on the item, leading to a negative leftover utility.

ii) On the other hand, if her reference price is less than her valuation for it, then she is not willing to pay as much as her valuation for the item, leading to a positive leftover utility. 
Proof. Given $P\left(v^{R} ; p^{R}\right)=v$, from Axiom 3a) and b) it is immediate that $p^{R}>$ $(<) v$ implies $v^{R}>(<) v$.

Proposition 1 provides a simple explanation for some important stylized facts along the lines of the health club scenario mentioned in the Introduction: on the one hand, in periods of generalized price reductions (sales) people tend to buy things that they do not really need (that is, they pay for the item more than what it is worth to them resulting in negative leftover utility) just because it is a "good deal" - in the sense that the price is lower than the reference price, which in this case can be identified with the pre-sale price; on the other hand, when people are bidding in an ascending price auction for an item that they value highly - in the sense that their valuation exceeds their reference price - even if they win it just when they were about to drop out (and hence they pay their WTP) they are usually happy with their purchase, indicating that away from the reference-price environment they are not truly indifferent: positive leftover utility.

This latter point underlines the importance of distinguishing what goes on in the consumer's mind at the time of the purchasing decision and once she has "cooled off". In Section 5, I will discuss this issue in more detail.

\subsubsection{Brand choice}

Assume the consumer has a unit demand but has several substitutes available for purchase. That is, her problem is

$$
\arg \max _{i} U\left(w-p_{i}^{p} ; i\right)
$$

where the second argument of the (indirect) utility function is the brand she ends up buying, with no purchase as $i=0, p_{0}=0$. As we are talking about substitutes, the reference price should be common to all brands. If the brands are perfect substitutes, in the sense that $U(x, i)=U(x, j)$ for all $x, i, j \neq 0$, then $\mathrm{RDP}$ will have no effect on the choice between brands, as it is order preserving: the consumer will always end up 
choosing the cheapest brand - both in terms of actual and perceived price - as long as she does purchase.

In general, the effects would depend on the exact specification of the price and utility functions. What we can say in general is that RDP will make it less/more likely that something with a price above/below the reference price is chosen.

If the distortion is increasing with the distance from the reference price, then it would always bias choice towards the cheaper alternatives.

\subsection{Multi-unit purchases}

The consumer's decision becomes more interesting when the choice variable is continuous, rather than binary. According to my formulation, there are no further degrees of freedom as to how to formalize this and the corresponding optimization problem is straightforwardly defined as

$$
x^{*}=\arg \max _{x \geq 0} U\left(w-p^{P} x ; x\right),
$$

where the second argument of the (indirect) utility function now signifies the (real) number of units bought. In other words, we simply substitute in the perceived price for the actual price in the standard model. Note that, since it is the unit price that is distorted, the distortion gets scaled up linearly by the amount bought. Hence ceteris paribus the (absolute) change in consumption as a result of RDP will be larger for consumers who really like the product and, therefore, consume a lot of it.

For all sensible utility functions, when the standard model leads to downward sloping demand, so does this one - even though in the conditions for optimum, we are evaluating the derivatives of these utility functions at different values in the two models.

If demand is downward sloping in the perceived price, then we have that a positive (negative) price surprise, $p^{R}-p>(<) 0$, increases (decreases) the amount bought relative to the standard model. To see this, just notice that, by Axiom 3d) and e), the perceived price is decreasing in $p^{R}-p$. 
As a straightforward consequence - holding the actual price constant - the total spend also varies in the same direction. This means that when a good is unusually cheap, the consumer actually spends more as a result of RDP. Similarly, observing an unexpectedly high price the consumer decreases the amount bought so that overall she ends up spending less than in the absence of RDP.

Proposition 2 If demand is decreasing in price, then - relative to the standard model - demand and expenditure are always higher (lower) if the actual price is below (above) the reference price, and vice versa.

In the multi-unit context, the discrepancy between valuation and WTP identified in Subsection 3.1.2 transmutes into a "rotation" of the original (inverse) demand function (which assigns a "valuation" to each quantity) around the point on it at the reference price, leading to higher WTP for quantities above the reference quantity and lower WTP for quantities below it. I will return to the discussion of the distorted (aggregate) demand function in Section 4, where I analyze the sellers' reaction to it.

Implicitly, these results also tell us how the quantity purchased of the other goods will vary with the RDP of a given good, as - in addition to substitution (or complementarity) effects - the money left over for those purchases will change:

\subsection{Cross-demand effects}

Assume that, for the purpose of this analysis, the groupings of categories into the same period are exogenously given - say, because they are sold in the same shop (or even in the same aisle). To simplify matters, assume that there is only one good subject to RDP and the rest can be bundled together as if they were a single commodity - the demand for which we call cross demand. We then have the following result, which follows from Proposition 2:

Corollary 1 Relative to the standard model 
1. If cross demand is increasing in the reference-distorted price, then cross demand and cross expenditure are higher (lower) if this price is above (below) the reference price;

2. If cross demand is decreasing in the reference-distorted price, then cross demand and cross expenditure are lower (higher) if this price is above (below) the reference price.

This result leads to different predictions from the models that use the utility function as the vehicle for the reference price effect. I will discuss the differences in Section 5; now I turn to a more in depth analysis of how RDP affects the budget constraint.

\subsection{RDP and budgets}

Let us consider a consumer choosing her preferred bundle of $n$ goods given a budget. According to my theory, reference prices affect her choice via the prices only and, therefore, exclusively through the budget constraint. In effect, given her budget, $B$, she solves:

$$
\arg \max _{\mathbf{x} \geq 0} u\left(x_{1}, x_{2}, \ldots, x_{n}\right) \text { s.t. } \sum_{i=1}^{n} p_{i}^{P} x_{i} \leq B .
$$

A crucial consequence of this formulation is that the budget constraint will be satisfied for the perceived, rather than the actual prices. As a result, in general the consumer will either under- or overspend relative to her budget.

Understandably, this may sound odd at first. In the absence of a saving motive, spending less than the budget is sub-optimal, while spending more than it sounds infeasible. However, it actually makes a lot of sense, if one recalls that the static model with a budget constraint is just a sub-problem of a dynamic scenario. In principle, the consumer is faced with optimizing her life-time consumption plan. It is a simplification to assume that this can be disaggregated into static constrained choice 
problems. My basic assertion is that the amount of money available for consumption at a given point in time is not fixed. The budgets consumers use in their optimization are only 'notional,' they mainly exist to simplify the complexity of the problem. I am not assuming that budgets are fully elastic and income can costlessly be moved across periods. Rather, I claim that budgets are not fully inelastic. For most purchase decisions of most consumers (in developed countries) there is sufficient flexibility think of a credit card, for example - to borrow against future income at a (small) cost. Similarly, there is no major obstacle to saving, even retaining the real value of funds, so an underspend does not imply wasted resources.

The heterogeneity of budget elasticities in the population can be neatly captured by differing intensities of the reference-price effect $(\alpha)$. In fact, it may make sense to treat this parameter asymmetrically around the reference price. The amount spent by a person with low borrowing potential may not be much affected by unexpectedly low prices (low $\alpha$ ), but be still very sensitive to unexpectedly high prices (high $\alpha$ ). Note that this would be very similar to the effect of loss aversion.

We can go even a step further: it need not be the case that the consumer is faced with the problem of reconciling her expenditure with her budget constraint every time she makes a purchase. ${ }^{9}$ Solving problems like (5) are quite difficult for the average consumer, especially when they have lots of items to buy - think of a weekly grocery shopping, for example. The natural way boundedly rational consumers simplify their optimization problem is to have notional budgets also for subsets (categories) of the goods they are buying. ${ }^{10}$ So much for fruit, for milk products, for wine etc. Then they can separately optimize in each subset, but in the absence of hard budget constraints. The next subsection formalizes this idea.

\footnotetext{
${ }^{9}$ See Soman (2001) for a discussion (and test) of how spending behavior varies with the payment mechanism, where the main distinctions are the "rehearsal" and immediacy of payments.

${ }^{10}$ See Heath and Soll (1996) and Thaler (1999), for a discussion of theory and evidence on the mental budgeting process.
} 


\subsection{A simple model of consumer behavior}

Let the planning horizon of our consumer be $T$ periods. She has some disposable income, $M$, for the planning horizon, to spend on planned purchases. There are $K$ $\geq T$ categories of goods that she buys. We denote by $x_{k}$ the amount (or quality ${ }^{11}$ ) she purchases of each category. Based on her experience and the available information, she forms an expectation of the price for each category, $p_{k}^{E}$. She can then calculate the optimal bundle to buy during the planning horizon using these expected prices (that is, her reference prices). This will result in notional budgets for each period.

From the consumer's point of view, actual prices are random and she only finds them out when she observes them, period by period. As the actual price may differ from the expected one, the consumer may suffer a "sticker shock". The effect of such a surprise is a price distortion, which is modelled following Section 2 of this paper. As argued above, this may lead to an outlay which is either above or below the notional budget.

Crucially, however, the imbalance need not affect consumer behavior in the subsequent decisions (within the same planning horizon). Note that the consumer does "feel" that she has just spent her notional budget, even if this is not the case. Consequently, until she "counts her money" and re-optimizes ${ }^{12}$ - which I assume she is doing every $T$ periods - the amount actually spent in a period will not influence her behavior in the other $T-1$ periods. The length of the planning horizon, $T$, is thus an important parameter. With suitably chosen planning horizons - which could correspond to the frequency with which she receives income - the consumer can simply take stock and redo her lifetime optimization based on her realized wealth (and updated reference prices) at that moment.

\footnotetext{
${ }^{11}$ In order to interpret $x_{k}$ as the quality rather than quantity of a product, we might need to consider non-linear prices. While this is clearly doable, for simplicity, I stick to linear prices here.

${ }^{12}$ That the frequency with which consumers (or investors) take stock of their activities can be a relevant parameter was first shown in Benartzi and Thaler (1995), where they explain the equity premium puzzle by using loss aversion and yearly evaluation of stock returns.
} 
An interesting question is how a consumer who knew that she suffered from reference-price bias, would try to mitigate its effects. ${ }^{13}$ As at the time of purchase she cannot help herself, a way to influence her decision is by setting "sub-optimal" notional budgets. Note that decreasing the soft budget assigned to a (joint) purchasing decision unambiguously lowers the amount spent (for every realization of the actual price). With Cobb-Douglas preferences, the variance of the amount spent also decreases, as the purchase decisions are separable and the notional budget, $B^{n}$, enters the error term multiplicatively: $\left(1-\frac{p}{p^{P}}\right) B^{n}$. Thus, under the reasonable assumption that overspending is more costly than underspending, Cobb-Douglas preferences should lead to conservative notional budget assignments. This is consistent with Pennings et al. (2005) where they find that budget-constrained consumers tend to spend less than their budget.

Note, however, that for other types of preferences the result is not obvious, as in the calculation of the variance of spending the covariances enter the picture. For example, if there are two goods and the consumer has a very high reference price for one of them but a very low one for the other the expected value of $\left(p_{1}^{P}-p_{1}\right)\left(p_{2}^{P}-p_{2}\right)$ will be negative, which might lead to the overall variance being decreasing in the notional budget.

An alternative way to mitigate the effects of a sudden budget squeeze when an overspend is detected, is to order the purchases hierarchically across planning horizons, making the favorite purchases first and leaving the less important ones exposed to a possible budget readjustment, much in the same way as time is budgeted by rational individuals.

\footnotetext{
${ }^{13}$ This is related to the idea that mental budgeting can be used for self-control purposes, c.f. Thaler and Shefrin (1981).
} 


\section{The implications of RDP for firms}

In this section I show that the aggregate effect of the consumers' RDP is to make the (residual) demand curve more elastic, and consequently it results in lower prices in monopoly and in imperfect competition (even with differentiated products). While the derivation of these results is quite straightforward, they serve as good vehicles towards a better understanding of the mechanics of the distortion and they also lead to empirically relevant (and perhaps testable) predictions, making their discussion worth the while. In our main discussion I will assume that the reference price is the one the consumers rationally expect in equilibrium, given that their RDP is common knowledge.

\subsection{Monopoly}

Assume that in the standard context (without RDP), aggregate demand would be given by the differentiable function, $D(p)$, where $D(1)=0$ and $-\infty<\frac{d D(p)}{d p}<0$, for all $p \in(0,1]$. Assume as well that the demand function satisfies the monotone hazard-rate property - that is, that $D(.) / D^{\prime}($.$) is increasing.$

Fixing, for simplicity, the cost of production at zero, it is immediate that the monopoly price, $p^{M}$, is the unique solution to

$$
D\left(p^{M}\right)=-p^{M} D^{\prime}\left(p^{M}\right)
$$

Now, suppose that the monopolist is aware that consumers perceive prices according to Axioms 1-3, with a common reference price - this will follow endogenously and the same price function - just for simplicity - for all.

Let us denote the "new" demand curve by $D_{R}($.$) . Then we have that D_{R}(p) \equiv$ $D\left(P\left(p ; p^{R}\right)\right)$. By Axiom $\left.3 \mathrm{c}\right), D_{R}\left(p^{R}\right)=D\left(p^{R}\right)$, that is, at the reference price the two demand curves coincide. In addition, we also have that $D_{R}(p)<D(p)$ for $p>p^{R}$ and $D_{R}(p)>D(p)$ for $p<p^{R}$. In other words, $D\left(P\left(p ; p^{R}\right)\right)$ is qualitatively a clockwise rotation of $D(p)$ around the point $\left(p^{R}, D\left(p^{R}\right)\right)$. 
What will the new monopoly price be?

We can write total revenue as $p D\left(P\left(p ; p^{R}\right)\right)$, yielding the first-order condition

$$
D\left(P\left(p^{M R} ; p^{R}\right)\right)=-p^{M R} D^{\prime}\left(P\left(p^{M R} ; p^{R}\right)\right) P_{1}\left(p^{M R} ; p^{R}\right) .
$$

Note that the optimal adjusted monopoly price, $p^{M R}$, will be a function of the (common) reference price of the consumers.

If it is common knowledge that the monopolist is aware of the RDP of consumer demand, then the consumers rationally expect the monopolist to set a price solving (7). This price will naturally play the role of the reference price in their price function. To rationalize the consumers' expectation, the reference price must then be equal to the optimal monopoly price, leading to a fixed-point argument.

Proposition 3 The monopoly price under a rationally expected reference price is lower than the monopoly price in the absence of a reference price: $p^{R E}<p^{M}$.

Proof. If the price function is differentiable, any RE price is given by a solution ${ }^{14}$ to $(7)$, with $p^{R}=p^{M R}$ :

$$
D\left(p^{R E}\right)=-p^{R E} D^{\prime}\left(p^{R E}\right) P_{1}\left(p^{R E} ; p^{R E}\right) .
$$

By Assumption $1, P_{1}(p ; p)>1$ for all $p$. By the monotone hazard-rate property of the demand function, this implies $p^{R E}<p^{M}$ for all solutions to (8).

When there is a kink at the reference price, we need to look at directional derivatives. Let us denote the operators for left and right derivatives $d_{L} / d$ and $d_{R} / d$, respectively. Then the (local) incentive constraints that need to be satisfied at $p=p^{R E}$ can be rewritten as

$$
\begin{aligned}
& D\left(P\left(p, p^{R E}\right)\right) \leq-p D^{\prime}\left(P\left(p, p^{R E}\right)\right) \frac{d_{L} P\left(p, p^{R E}\right)}{d p} \\
& D\left(P\left(p, p^{R E}\right)\right) \geq-p D^{\prime}\left(P\left(p, p^{R E}\right)\right) \frac{d_{R} P\left(p, p^{R E}\right)}{d p} .
\end{aligned}
$$

\footnotetext{
${ }^{14}$ The solution exists as $-D(.) / D^{\prime}($.$) is continuously decreasing from a positive value to zero, while$ $p^{R E} P_{1}\left(p^{R E} ; p^{R E}\right)$ is continuous, starts at zero and it is positive ever after. A sufficient condition for uniqueness is that $p P_{1}(p ; p)$ is increasing in $p$.
} 
Since $\frac{d_{L} P\left(p, p^{R E}\right)}{d p}>1$, there is a clear incentive to decrease the price from any reference price weakly above the monopoly price.

The intuition for the result is clear: as the (inverse) demand function is "rotated" counter-clockwise, the price elasticity of demand is increased at the original monopoly price, so unit-elasticity is reached at a lower price.

\subsubsection{Heterogeneous price functions}

If different consumers have different price functions, but the distribution of those is common knowledge, then generically the same analysis applies. As long as the monopolist has a unique best response (that is, the distribution of price functions is "well behaved"), this will serve as the reference price for all consumers. Given the common reference price all the consumers will experience a price distortion in the same direction both above and below the reference price.

\subsubsection{Adaptive expectations}

Instead of having forward looking "rational expectations", we could have our consumers react adaptively to new information. Imagine that they all start out with different reference prices, the distribution of which is known to the monopolist. Then the monopolist will best respond to these, setting her optimal price. Upon observing this price, the consumers will update their reference prices, replacing it with the current price. The monopolist then best responds to this reference price, the consumers update, and so on. In this manner a process of tâtonnement will ultimately drive the market to the fixed point derived above. ${ }^{15}$

\footnotetext{
${ }^{15}$ We could equally have consumers just move their reference prices towards the current price, rather than replacing it with it. This would mean that the reference prices only get homogenized in the limit, but would not change the limit price itself.
} 


\subsection{Oligopoly}

In this section we investigate to what extent the price reducing effect observed in the monopoly context carries over to a market with (imperfect) competition.

\subsubsection{Homogeneous goods, price competition}

In a Bertrand set-up the RDP is dwarfed by the effect of "head-on" competition. As the firm undercutting the rest receives the entire market demand, small distortions in it do not affect behavior. Nonetheless, if the marginal costs are different, there is a scenario in which RDP may make a difference. Recall that in asymmetric Bertrand competition the lowest cost seller serves the entire demand. In equilibrium, she charges the second lowest cost - unless the monopoly price is below that cost. As we have seen, RDP reduces the optimal monopoly price, and hence it is possible that as a result of RDP the Bertrand equilibrium price is lowered: from the second lowest cost to the RDP affected monopoly price.

\subsubsection{Homogeneous goods, quantity competition}

It is quite intuitive that the effects observed in case of monopoly will also appear when an oligopolist reacts to a residual demand curve. In order to establish this result, we first need to elaborate how the Cournot model works under RDP. The easiest way to formalize this is by observing that all the changes in consumer behavior are captured in the "new" demand function, $D_{R}(p)=D\left(P\left(p ; p^{R E}\right)\right)$, where $p$ is the actual price. Thus, if the total quantity produced is $Q=\sum q_{i}$, then the actual price is $D_{R}^{-1}(Q)$ and the perceived one is $P\left(D_{R}^{-1}(Q) ; p^{R E}\right)$. In rational expectations equilibrium, these two must coincide.

Based on the above observation, we can use the standard analysis, all we need to do is substitute in the more price elastic demand function. Let us write the total revenue of producer $i$ as $p q_{i}$. This leads to the first-order condition

$$
\frac{\partial p}{\partial q_{i}} q_{i}+p=\frac{\partial D_{R}^{-1}\left(\sum q_{i}\right)}{\partial q_{i}} q_{i}+p=0 .
$$


Noting that $\frac{\partial D_{R}^{-1}\left(\sum q_{i}\right)}{\partial q_{i}}=\frac{1}{D_{R}^{\prime}\left(D_{R}^{-1}\left(\sum q_{i}\right)\right)}=\frac{1}{D_{R}^{\prime}(p)}$ and that $n q_{i}=D_{R}(p)$, we obtain the equilibrium condition

$$
\frac{D_{R}(p)}{D_{R}^{\prime}(p)}=-n p .
$$

Let $p^{C}(n)$ denote the standard Cournot price, defined by $D\left(p^{C}(n)\right)=-n p^{C}(n) D^{\prime}\left(p^{C}(n)\right)$. When this is the reference price, $D_{R}\left(p^{C}(n)\right)=D\left(p^{C}(n)\right)=-n p^{C}(n) D^{\prime}\left(p^{C}(n)\right)<$ $-n p^{C}(n) D_{R}^{\prime}\left(p^{C}(n)\right)$, as the "new" demand function is more elastic at the reference price. ${ }^{16}$ As a consequence, the resulting Cournot price, $p^{C R E}(n)$, must be lower. Thus, we have shown that

Proposition 4 The Cournot price under a rationally expected reference price is strictly lower than the Cournot price in the absence of a reference price: $p^{C R E}(n)<$ $p^{C}(n)$, and hence the quantity produced is larger. Thus, RDP makes competition more intense.

Let us turn to the interplay between the amount of competition and RDP next. In order to be able to look at comparative statics, let us assume that (inverse) demand is linear, given by $p=A-Q$. Also, let us use the specific functional form proposed for the price function above, (1). Straightforward calculations show that the resulting equilibrium price will be given by $p^{C R E}(n, \alpha)=\frac{A}{1+n(1+\alpha)}$. Thus, as expected, the price reduction is increasing in the intensity of RDP. While the absolute change resulting in the equilibrium price is clearly decreasing, the proportional change is actually increasing in the number of competitors: $\frac{d\left(p^{C R E}(n, \alpha) / p^{C R E}(n, 0)\right)}{d n}=-\frac{\alpha}{(1+n(1+\alpha))^{2}}<0$. Unlike in the Bertrand case, the intensity of Cournot competition does not crowd out the RDP effect.

\subsubsection{Horizontally differentiated products}

In a symmetric Hotelling set-up, the reference price will be the common equilibrium price. For any transportation cost that does not cause technical difficulties, the

\footnotetext{
${ }^{16}$ When the price function, and thus the demand function, is not differentiable at the reference price, we can just substitute in the left derivative and the same argument goes through.
} 
demand functions once again become more own-price elastic with RDP. Thus, for fixed locations, prices will be lower with reference-price effects than in the standard context.

As a further consequence, the increased price competition will tend to increase the incentives for differentiation relative to the standard case.

If the firms are not symmetric, the reference price is not so easily identified, as they are going to charge different prices. However, based on either range or frequency theories the literature would lead to a reference price as some weighted average of the prices charged. In the case of a duopoly, this would mean that the firm setting the lower price is helped while the other is hurt by RDP. This will clearly decrease the higher of the two prices, while the effect on the lower price is indeterminate in general.

In a monopolistically competitive market, again prices will be lower with RDP. This will alleviate the problem of operating below the efficient scale, but increase the business stealing effect. As a result, the overall impact on the amount of entry is dependent on the specific functional forms.

\subsubsection{Vertically differentiated products with an incumbent and an entrant}

Finally, let us investigate how RDP influences the competition between an incumbent monopolist and an entrant producing an inferior substitute. This setup is motivated by the wide-spread concern that globalization (understood as unrestricted international trade) undermines the market viability of locally produced high quality goods (c.f. Kiyotaki and Moore, 2003).

Assume that the incumbent (Firm 1) and the entrant (Firm 2) are located at the two endpoints of a two-unit-long Hotelling interval. Consumers are uniformly distributed between the incumbent and the midpoint of the interval, capturing the incumbent's quality advantage. Travel costs are linear and each consumer values the good at 2 minus his travel cost. Finally, the constant marginal cost of the incumbent 
is $c$, while that of the entrant is zero, allowing for a cost advantage to the low quality producer. In this scenario it is natural that the reference price is given by the price charged by the incumbent following the entry of the low quality firm, even if prices are set simultaneously.

Proposition 5 As a result of RDP, the incumbent is forced to reduce its price further, making it worse off.

Proof. Note that as the reference price is $p_{1}$, the leader's prices are not distorted: $p_{1}^{P}=p_{1}$. The marginal consumer is given by the $x$ value solving $x+p_{1}=2-x+p_{2}^{P}$, leading to $x^{*}\left(p_{1}, p_{2}\right)=\frac{2+p_{2}^{P}-p_{1}}{2}$. Let us denote $\frac{\partial p_{2}^{P}\left(p_{2}^{*} ; p_{1}^{*}\right)}{\partial p_{i}}$ by $p_{i}^{\prime}$. The profits of Firm 1 are given by $\left(p_{1}-c\right) x^{*}\left(p_{1}, p_{2}\right)$, leading to the best response function $p_{1}\left(p_{2}\right)=\frac{2+c+p_{2}^{P}-c p_{1}^{\prime}}{2-p_{1}^{\prime}}$. Under full market coverage, the entrant's problem is to maximize $p_{2}\left(1-x^{*}\left(p_{1}, p_{2}\right)\right)$, which leads to the (implicit) best response function $p_{2}\left(p_{1}\right)=\frac{p_{1}-p_{2}^{P}}{p_{2}^{\prime}}$. Without specifying the price function we cannot solve for the resulting prices. Nonetheless, we can deduce some qualitative comparative static results. By Axiom 3d), we know that $p_{1}^{\prime}<0$ and $p_{2}^{\prime}>1$. As a result, we can show that the incumbent's best response function is lower as a result of RDP. To see this, first note that $\frac{\partial p_{1}\left(p_{2}\right)}{\partial p_{1}^{\prime}}=2-c+p_{2}^{P}>0$, which - together with $p_{1}^{\prime}<0$ - directly implies that the incumbent's reaction is more aggressive than in the standard model. In turn, $p_{2}^{\prime}>1$ and $p_{2}^{P}<p_{2}$ imply that $p_{2}^{P}\left(p_{1}\right)<\frac{p_{1}}{2}$. Thus, at least as it is perceived by consumers, the entrant's price reaction is also more competitive. The lower perceived price of the entrant shifts the residual demand downward, ensuring that even following its best response (a price reduction) the incumbent will be worse off.

The intuition is quite clear even without a formal analysis. As the entrant always sets the lower price in equilibrium, RDP will always have a favorable effect on its perceived price, increasing its competitive edge. As perceived prices are strategic complements, the incumbent is forced to lower its price to counteract. Note that it is indeterminate whether the actual price charged by the entrant will go up or down as a result of RDP. Thus, while the incumbent loses due to RDP, the effects on the 
entrants profit, the market shares and consumer welfare depend on the specifics of the price function.

An interesting feature of this price setting game is that despite the simultaneity of offers, as the reference price is set by the incumbent, it has a Stackelberg flavor. Note that even taking the actual price of the entrant as a parameter (as one should when calculating a best response function), the incumbent alters the perceived price of the entrant's good by varying its own price: when the incumbent lowers its price, not only will its good become more attractive but the entrant's price will look less good to the consumers, as their reference price has decreased. Due to this "double whammy" the overall (Bertrand) equilibrium effect of RDP is a lower price charged by the incumbent. In the sequential price setting game an additional effect would come into play: we would have to take the total (rather than just the partial, as

above) derivative of $p_{2}^{P}$ relative to $p_{1}$, adding a term which - because of strategic complementarity - is increasing in the incumbent's price. As a result the overall effect would depend on the specific price function.

\section{Comparison with the transaction utility approach}

Thaler (1985) proposes a decomposition of the change in a consumer's utility as a result of buying an item into two - additive - components. The first one is just the standard change as a result of paying the price and gaining the item - the "acquisition utility" - while the second component is a function of the difference between the price and the reference price, which he calls "transaction utility", $t\left(p^{R}-p\right)$. This function is assumed to be increasing, convex below and concave above zero, with $t(0)=0$. In other words, "good" surprises give a positive kick, while "bad" ones result in a negative utility shock. He also assumes that the negative shocks are larger and thus the term exhibits loss aversion $\left(t\left(p-p^{R}\right)<-t\left(p^{R}-p\right)\right.$ for $\left.p>p^{R}\right)$.

Formally, in my notation, Thaler defines the consumer's WTP as the price which 
solves

$$
U(w ; 0)=U(w-p ; 1)+t\left(p^{R}-p\right) .
$$

Implicitly defining $P^{\prime}\left(p ; p^{R}\right)$ as $U\left(w-P^{\prime}\left(p ; p^{R}\right) ; 1\right) \equiv U(w-p ; 1)+t\left(p^{R}-p\right)$, we can reproduce the Thaler set-up (c.f. (2) and (10)) as long as the resulting $P^{\prime}\left(p ; p^{R}\right)$ satisfies Axiom 3. Using the fact that utility is strictly increasing in wealth, this can be easily verified (see Proposition 6 below) - sometimes we would need a negative perceived price to capture the additional utility incorporated in the transaction utility term for low actual prices, but that is compatible with Axiom 3. It is also easy to see that loss aversion would indeed translate to a higher directional derivative below the reference price than above it. Note, however, that the price-function approach is more general, as the above process cannot be inverted: in general, the resulting transaction utility will depend on $p$ in a more complex way than simply on the difference, $p-p^{R}$, as the following example illustrates.

Example 1 Let $P\left(p ; p^{R}\right)=p^{R}+\alpha\left(p-p^{R}\right)$, with $\alpha>1$, and $U(x ; 1)=\ln (x)$. We then have that $t\left(p, p^{R}\right)=U\left(w-P\left(p ; p^{R}\right) ; 1\right)-U(w-p ; 1)=\ln \frac{w-p^{R}+\alpha\left(p-p^{R}\right)}{w-p}$.

This asymmetry is due to the more permissive definition of the price function, which does not restrict the functional form to depend only on the difference between the price and the reserve price (c.f. Axiom 3). If we thought that such a restriction had to be satisfied, then in general the two approaches would not be compatible. Going the other way, relaxing the original restrictions on the transaction utility term, outcome equality between the two approaches could be restored, with some restrictions, as discussed below.

Even if the choices made following either of the two approaches coincide, the consumer's utility derived from the purchase will be different. My model implies that only the acquisition utility matters, while the Thaler approach would take full account of the transaction utility as well, and consequently could not explain the fitness club 
scenario at the beginning of this paper. ${ }^{17}$ Note that by comparing (3) with (10) we can, in principle, identify the leftover utility as $t\left(p^{R}-v^{R}\right)$ : the transaction utility gained when the actual price makes the consumer with RDP indifferent. This is only a quantitative identity. The crucial difference is that the transaction utility is supposed to be something the consumer actually enjoys/suffers in addition to the acquisition utility, while leftover utility is not an actually felt utility, rather it is the artificial construct of the difference between acquisition utility at price $p=v^{R}$ and the counterfactual option of not having bought. Alternatively, the leftover utility is the actual change in acquisition utility moving from a reference-price environment to a reference-free environment, when $p=v^{R}$ - that is, when a RDP consumer is indifferent. By (10), there would be no such change in the transaction utility framework.

My claim is that the reference-price bias has a larger impact at the point of the purchasing decision than the transaction utility's share of total utility. Soon after the purchase the reference-price effect fades away. Thus, the discounted lifetime value of the good (the acquisition utility) is likely to dwarf the transaction utility. However, at the time of trade, the reference-price effect can be very strong. My model allows for incorporating that strong effect without distorting welfare. Of course, the best model is probably a combination of the two. It would be straightforward to include a transaction utility term as well as the price distortion. For now, it seems more didactic to concentrate on the extreme case where the price function replaces transaction utility.

When the choice ceases to be binary, it is unclear how Thaler's theory should be generalized. Note that - unlike in the present model - it is not predetermined how the transaction utility should vary with the quantity purchased. If we added a quantity-independent transaction utility term to the objective function, the chosen

\footnotetext{
${ }^{17}$ Even ex post, the consumer would have to admit that she received a utility shock - the transaction utility - at the time of purchase, so her evaluation of the deal should not vary with the sign of the difference between the reference and purchase prices.
} 
amount would be unaffected (conditional on a purchase), as the transaction utility (as defined in Thaler, 1985) only depends on the unit price and not on the total spend. Alternatively, we could define transaction utility to be a flexible construct: $t\left(x, p ; p^{R}\right)$. As a natural extension of the original concept we would want the transaction utility to satisfy the following

\section{Assumption 2 1. $t\left(x, p^{R} ; p^{R}\right)=0$;}

2. $t\left(x, p ; p^{R}\right)>0$ if $p<p^{R}$;

3. $t\left(x, p ; p^{R}\right)<0$ if $p>p^{R}$;

4. $\frac{d t\left(x, p ; p^{R}\right)}{d p}<0$

5. $\frac{d\left|t\left(x, p ; p^{R}\right)\right|}{d x}>0$;

6. $\frac{d t\left(x, p ; p^{R}\right)}{d p^{R}}>0$.

In the sequel, we will also need to refer to the following assumption, which imposes a lower bound on the slope of the price function.

Assumption 3 The price function satisfies

$$
\frac{d P\left(p ; p^{R}\right)}{d p}>\frac{U^{\prime}\left(w-x P\left(p ; p^{R}\right) ; x\right)}{U^{\prime}(w-x p ; x)} .
$$

We can now state the "outcome equivalence" result formally. Its proof is in the Appendix.

Proposition 6 For any transaction utility function satisfying Assumption 2, there exists a price function satisfying Axiom 3 and Assumption 1, such that the consumer's choice is the same. However, only for a price function satisfying Assumption 3 in addition to Axiom 3 and Assumption 1 there exists a transaction utility function satisfying Assumption 2, such that the consumer's choice is the same. 
The conditions $t\left(x, p ; p^{R}\right)$ needs to satisfy for outcome equivalence with the price function approach are the ones we would expect. ${ }^{18}$ There is a single discrepancy: in order to ensure that the transaction utility is decreasing in the price, we need the price function to be sufficiently steep, ruling out a scenario where for prices away from the reference price the distortion diminishes.

Even if unconstrained optimization would lead to the same choice, in the presence of a budget, differences would arise. Under transaction utility, by definition, the chosen basket would lead to a spend equal to the available amount, leading to different predictions compared to RDP. For example, if all goods resulted in a similar sticker shock, the outcome (though not the welfare) would be the same as without the surprise. In my model, the consumer would adjust total spending according to the sign of the common shock. Similarly, for complementary goods the effects on cross demand are in opposing directions for the two approaches. As a consequence of RDP, Corollary 1 of this paper predicts movement in the same direction for the consumption of both goods, while Thaler's model would imply changes in opposing directions (or, for Leontieff preferences, no change at all).

\section{Conclusion}

In this paper I propose a fresh way of looking at reference price effects in a model of consumer choice. The idea that it is the prices, not the preferences that are distorted by the reference price has a number of at first blush surprising consequences, which nonetheless can be readily rationalized: witness the concept of a soft budget constraint. At this stage we do not have the data that could give the proposed model full empirical validity, so we have to do with the weaker defense that it can explain some stylized facts. At the same time, to the extent that the role of theory is to train our intuition, thinking outside the box by moving the reference price out of the utility function is a worthwhile exercise in its own right.

\footnotetext{
${ }^{18}$ Of course, the different welfare effects would still remain.
} 
While I have provided several testable predictions, there are lots of implications of my approach that could not be analyzed here and are left for future research. I am especially thinking of models of negotiation and dynamic pricing. As an example, RDP could be behind the experimental results on bargaining, which are usually explained by people having a mixture of "social" and selfish preferences (c.f. Bolton, 1991). The reference price may be seen as the "social focal point". One could analyze standard bargaining protocols with players "suffering" from reference price bias and explain bargaining data without invoking a conscious fairness motive.

\section{References}

[1] Anderson, N.H. (1981) Foundations of Integration Theory, New York: Academic Press.

[2] Ariely, D., Köszegi, B., Mazar, K. and Shampan'er, K. (2004) "Price-Sensitive Preferences," mimeo. UC Berkeley, May.

[3] Beggs, A. and Graddy, K. (2006) "Anchoring effects: Evidence from Art Auctions," mimeo. Oxford, November.

[4] Bell, D.R. and Lattin, J.M. (2000) "Looking for loss aversion in scanner panel data: The confounding effect of price response heterogeneity," Marketing Science, 19(2), 185-200.

[5] Benartzi, S. and Thaler, R. (1995) "Myopic Loss Aversion and the Equity Premium Puzzle," Quarterly Journal of Economics, 110(1), 73-92.

[6] Biswas, A., and Blair, E.A. (1991) "Contextual effect of reference prices in retail advertisements," Journal of Marketing, 55, 1-12.

[7] Bolton, G. (1991) "A comparative model of bargaining: Theory and evidence," American Economic Review, 81, 1096-1136. 
[8] Briesch, R.A., Krishnamurthi, L., Mazumdar, T., and Raj, S.P. (1997) "A comparative analysis of reference price models," Journal of Consumer Research, 24, 202-214.

[9] Deaton, A. (1977) "Involuntary Saving Through Unanticipated Inflation," American Economic Review, 67(5), 899-910.

[10] Genesove, D. and Mayer, C. (2001) "Loss Aversion and Seller Behavior: Evidence from the Housing Market," Quarterly Journal of Economics, 116(4), 1233-1260.

[11] Hardie, B.G.S., Johnson, E.J., and Fader, P. S. (1993) "Modeling loss aversion and reference dependence effects on brand choice," Marketing Science, 12, 378394.

[12] Heath, C. and Soll, J.B. (1996) "Mental Budgeting and Consumer Decisions," Journal of Consumer Research, 23(1), 40-52.

[13] Heidhues, P. and Köszegi, B. (2005) "The Impact of Consumer Loss Aversion on Pricing," mimeo. UC Berkeley, May.

[14] Heidhues, P. and Kőszegi, B. (2008) "Competition and Price Variation when Consumers are Loss Averse," The American Economic Review, 98(4), 1245-1268.

[15] Jacoby, J. and Olson, J.C. (1977) "Consumer Response to Price: An Attitudinal, Information Processing Perspective," in Moving Ahead with Attitude Research, Y. Wind and P. Greenberg, eds. Chicago: American Marketing Association. 7386.

[16] Janakiraman, N., Meyer, R.J. and Morales, A.C. (2006) "Spillover Effects: How Consumers Respond to Unexpected Changes in Price and Quality," Journal of Consumer Research, 33(3), 361-369.

[17] Kalyanaram, G., and Winer, R.S. (1995) "Empirical generalizations from reference price research," Marketing Science, 14, G161-G169. 
[18] Kiyotaki, N., and Moore, J. (2003) "A Cost of Unified Currency." In Central Banking, Monetary Theory and Practice: Essays in Honor of Charles Goodhart, Vol. 1, edited by Paul Mizen, 247-255. Cheltenham, UK: Edward Elgar.

[19] Kőszegi, B. and Rabin, M. (2006) "A Model of Reference-Dependent Preferences," Quarterly Journal of Economics, 121(4), 1133-1066.

[20] Mazumdar, T., Raj, S.P. and Sinha, I. (2005) "Reference Price Research: Review and Propositions," Journal of Marketing, 69, 84-102.

[21] Niedrich, R.W., Sharma, S. and Wedell, D.H. (2001) "Reference Price and Price Perceptions: A Comparison of Alternative Models " Journal of Consumer Research, 28(3), 339-354.

[22] Pennings, J.M.E., van Ittersum, K. and Wansink, B. (2005) "To spend or not to spend? The effect of budget constraints on estimation processes and spending behavior," Advances in Consumer Research, 32, 328-329.

[23] Putler, D.S. (1992) "Incorporating Reference Price Effects into a Theory of Consumer Choice," Marketing Science, 11(3), 287-309.

[24] Schindler, R.M., and Kibarian, K.M. (1996) "Increased consumer sales response through use of 99-ending prices," Journal of Retailing, 72(2), 187-199.

[25] Soman, D. (2001) "Effects of Payment Mechanism on Spending Behavior: The Role of Rehearsal and Immediacy," Journal of Consumer Research, 27(4), 460474.

[26] Thaler, R. (1980) "Toward a Positive Theory of Consumer Choice," Journal of Economic Behavior and Organization, 1, 39-60.

[27] Thaler, R. (1985) "Mental Accounting and Consumer Choice," Marketing Science, 4(3), 199-214. 
[28] Thaler, R. (1990) "Saving, Fungibility and Mental Accounts," Journal of Economic Perspectives, 4(1), 193-205.

[29] Thaler, R. (1999) "Mental Accounting Matters," Journal of Behavioral Decision Making, 12(3), 183-206.

[30] Thaler, R. and Shefrin, H.M. (1981) "An Economic Theory of Self-Control," Journal of Political Economy, 39, 392-406.

[31] Tversky, A. and Kahneman, D. (1991) "Loss Aversion in Riskless Choice: A Reference-Dependent Model," Quarterly Journal of Economics, 106(4), 10391061.

[32] Winer, R. (1986) "A Reference Price Model of Brand Choice for Frequently Purchased Products," Journal of Consumer Research, 13, 250-256.

[33] Zeithaml, V.A. (1988) "Consumer Perceptions of Price, Quality, and Value: A Means-End Model and Synthesis of Evidence," Journal of Marketing, 52(3), 2-22.

\section{Part I}

\section{Appendix}

Here I show that - in the absence of a binding wealth constraint - an outcome equivalence result holds between the generalized transaction-utility and the RDP approaches.

Proof. (of Proposition 6) A sufficient condition for the result is to establish that

$$
U(w-x p ; x)+t\left(x, p ; p^{R}\right)=U\left(w-x P\left(p ; p^{R}\right) ; x\right)
$$

implies that whenever $t$ satisfies Assumption 2, P satisfies Axiom 3 and Assumption 1 and vice versa. Let us begin with the if part. As utility is strictly increasing, we 
can invert it in its first argument (holding the second constant) and thus we can solve (11) for $P$ :

$$
P\left(p ; p^{R}\right)=\frac{w-U^{-1}\left(U(w-x p)+t\left(x, p ; p^{R}\right)\right)}{x} .
$$

As $t(0)=0$, it is immediate that $P\left(p^{R} ; p^{R}\right)=p^{R}$. Let $p^{R}>(<) p$, implying that $t\left(x, p ; p^{R}\right)>(<) 0$. As $U($.$) is increasing so is U^{-1}($.$) , so U^{-1}\left(U(w-x p)+t\left(x, p ; p^{R}\right)\right)>$ $(<) w-x p$, hence $P\left(p ; p^{R}\right)<(>) p$. Differentiating (12) with respect to $p$ we get $\frac{x U^{\prime}(w-x p)-d t / d p}{x U^{\prime}\left(U^{-1}\left(U(w-x p)+t\left(x, p ; p^{R}\right)\right)\right)}>0$, as $d t / d p<0$. Since from the previous step, for $p<p^{R}$, $U^{-1}\left(U(w-x p)+t\left(x, p ; p^{R}\right)\right)>w-x p$, the concavity of the utility function implies that the derivative is indeed above one, not just at $p=p^{R}$, but for all $p<p^{R}{ }^{19}$ Finally, differentiating (12) with respect to $p^{R}$, we get $\frac{-d t / d p^{R}}{x U^{\prime}\left(U^{-1}\left(U(w-p)+t\left(p^{R}-p\right)\right)\right)}$, which is clearly negative.

Turning to the only if part, from (11)

$$
t\left(x, p ; p^{R}\right)=U\left(w-x P\left(p ; p^{R}\right) ; x\right)-U(w-x p ; x) .
$$

It is straightforward that 1-3 of Assumption 2 are satisfied. Differentiating (13) with respect to $p$, we get $-x U^{\prime}\left(w-x P\left(p ; p^{R}\right) ; x\right) \frac{d P}{d p}+x U^{\prime}(w-x p ; x)$. In order for this to be negative we need

$$
\frac{d P}{d p}>\frac{U^{\prime}\left(w-x P\left(p ; p^{R}\right) ; x\right)}{U^{\prime}(w-x p ; x)},
$$

exactly as stated in Assumption 3.

Differentiating (13) with respect to $p^{R}$, we get $-x U^{\prime}\left(w-x P\left(p ; p^{R}\right) ; x\right) \frac{d P}{d p^{R}}$, which is clearly positive. Finally, differentiating (13) with respect to $x$, we get - for simplicity, I am assuming that the derivative with respect to the second argument of $U$ is approximately constant in the relevant range, and hence these terms cancel out $\frac{d t}{d x}=p U^{\prime}(w-x p ; x)-P\left(p ; p^{R}\right) U^{\prime}\left(w-x P\left(p ; p^{R}\right) ; x\right)$. This is positive when

$$
\frac{P\left(p ; p^{R}\right)}{p}<\frac{U^{\prime}(w-x p ; x)}{U^{\prime}\left(w-x P\left(p ; p^{R}\right) ; x\right)},
$$

which is satisfied if and only if $p<p^{R}$, exactly as needed. Q.E.D.

\footnotetext{
${ }^{19}$ That is, the transaction utility approach is not compatible with a price function that has no distortion at zero, implying that negative perceived prices are necessary for the equivalence to hold.
} 